\title{
To lock or not to lock? Mexico case
}

\author{
Giovanni Perea Tinajero ${ }^{1}$ (D) Agata Bąk $^{2}$ (D)
}

Received: 31 December 2020 / Accepted: 30 August 2021 / Published online: 11 November 2021 (C) Springer Nature Switzerland AG 2021

\begin{abstract}
In this paper, we analyze some of the policies implemented by Mexico, a country that has not pursued a total lockdown, although it has implemented different partial confinement policies. Such approach to the confinement has been criticized by some authors as morally inappropriate. Our focus is to show that cultural, political and economic conditions shape the governmental response to the pandemic. While these can be judged on the basis of their efficiency, it seems to us that underlying principles are also ethically acceptable.
\end{abstract}

Keywords Pandemic $\cdot$ Mexico $\cdot$ SARS-COV-2 $\cdot$ Governability $\cdot$ Lockdown

The SARS-COV-2 pandemic has rushed governments to implement different strategies in order to prevent massive death tolls. In this paper, we ask whether strict lockdowns constitute a unique and ethically correct answer to the challenges imposed by the pandemic. Some authors, for example Bramble (2020), suggest that only a general and strict lockdown is morally acceptable. Their main argument is that the correct moral view of the pandemic is not how many lives have been lost de facto, but how many would have been lost had we not implemented harsh policies (ib.). Opponents of this idea, on the other hand, argue that strict lockdowns bring a lot of collateral damage, ranging from deaths from other conditions that would have been

Giovanni Perea Tinajero giovanni.pereati@alumno.buap.mx

Agata Bąk

agatabak@madrid.uned.es

1 Facultad de Filosofía y Letras, Benemérita Universidad Autónoma de Puebla (BUAP), Puebla, México

2 Present Address: CA UNED, Universidad Nacional de Educación a Distancia, Gregorio Marañón, Madrid, Spain 
preventable in a non-lockdown scenario, to well-being, costs of unemployment and poverty (cfr. Kidds \& Rattcliffe, 2020a, 2020b). Further discussion focuses on the real efficiency of lockdowns regarding the flattening of the curve. The latter is not a debate we wish to engage in as we believe that with current data it is extremely difficult to distinguish between the de facto and the would-be scenarios. In this paper, we do not embrace an extreme position that would pursue an abolishment of all policies of control. Needless to add, we believe that in fact SARS-COV-2 constitutes a major worldwide challenge that needs to be addressed promptly. However, we do commit to the idea that social, cultural, economic, legal and historical factors have and should have an impact in shaping pandemic policies, as the outbreak does not happen only in the social void. In this context, we raise the question whether lockdowns should be treated as an absolute moral imperative. As Kidds and Rattclife point out, there is a certain moral superiority that advocates of strict confinements have: "They know what is happening; they know what is right; they know what to do" (ib.). In order to flesh out the doubts regarding this issue, we would like to focus on the specific challenges faced by Latin American countries, in particular, Mexico. The purpose is to showcase that partial and not total lockdown strategies seem to be guided by morally valid concerns rooted in a deeper social context that also pursue avoiding as many deaths as possible.

General WHO dispositions have been translated into different policies in different regions. The purpose is clear: to avoid, in as much as possible, deaths caused by the pandemic situation while also preserving the capacity of the healthcare systems to attend new cases in order to avoid impossible ethical decisions. This can be translated into different policies. In Mexico, the Subsecretary for Prevention and Health Promotion in the Federal Government, Hugo López-Gatell Ramírez, repeatedly claimed that the pandemic is not only a challenge of the propagation of the lethal virus, but also -or even mostly- a problem of social nature. It is particularly clear in the case of México, a decentralized, economically unequal, historically and geographically diverse country, with a hybrid and somewhat precarious healthcare system (basic social healthcare and a wide range of private and local systems).

At the time of writing this paper (December 2020), the situation in Mexico is serious. Confirmed SARS-COV-2 cases have skyrocketed, breaking the dreadful barrier of one million cases and the number of fatalities is above 100,000, one of the highest mortality rates in the world. As of today, Mexico has dropped out of the top ten countries with most detected cases, according to official numbers. The mortality rate is high and oscillates around $10 \%$ of the reported cases, but it is reasonable to think that the numbers are far superior. As of the beginning of December, the excess number of deaths hit 200,000, according to the governmental page ${ }^{1}$ (Gobierno de México, 2020). Testing is not massive in Mexico and it has the highest number of deaths among healthcare workers. Access to SARS-COV-2 treatment is public, however, problems may arise when accessing this healthcare service, especially in remote areas. The country has recently received a warning from WHO regarding

\footnotetext{
1 Gobierno de México, "Exceso de mortalidad en México" in https://coronavirus.gob.mx/exceso-demortalidad-en-mexico/ as seen on Dec, 3rd., 2020.
} 
its pandemic policies. Despite this alarming data, the country has never imposed a total lockdown on the totality of its population; a national state of emergency was declared on April the 1st, for one month, which amounted to a considerable confinement, but it has not been repeated since. Diverse strategies and recommendations were implemented, and indeed there were partial lockdowns, but their scope was not as wide as in other Latin American (eg. Chile) or European countries. Is it morally admissible? In what follows we would like to ponder some of the country's strategies in their respective context.

We believe that the communication and application of specific uniform and restrictive policies constitute a challenge in Mexico's particular scenario. The problem for Mexico is threefold: first, it is related to political and economic circumstances. Second, there is a need to understand the virus from a social and cultural dimension. And finally, it has to do with subjective and moral consideration. Needless to say, this revision does not amount to the appraisal of Mexican policies; rather, it seeks to analyze the presupposition they are based on.

Regarding the first aspect, on the federal level, Mexico has struggled to find a balanced policy between health protection and avoiding an economic catastrophe. This can be observed in the example of almost uninterrupted open borders. This openness seems to be a national tradition ranging from at least the XIX century up until the previous pandemic, the H1N1 flu (Córdova-Villalobos et al., 2009). While many countries closed or restricted the entry only to products and essential services, Mexico remained open, although it did impose several regulations in some algid periods.

This policy has been applied not only to commercial flights, which seems to obey the general assumption of "saving the economy". It has also been applied, although we can question its efficacy, to migrants and asylum seekers, whose number, according to a COMAR report (as quoted in Animal Politico, 2020), has considerably raised this year. Mexico is a country that historically has welcomed (some) refugees; nevertheless, it is also seen as a transit region of migratory routes heading towards the USA. In the current pandemic, it has also become a destination country. And while we cannot ignore sometimes serious irregularities pointed out by different NGOs, despite how slow migratory processes are, and even in the case of deportations, we need to ask if, in face of the current situation, it is not a morally correct position. At least in principle.

A word must also be said about state policies. Heterogeneous pandemic policies and healthcare are conditioned by state policies of each one of the 32 entities that integrate United States of Mexico (Estados Unidos Mexicanos). Each entity has independent sovereignty. This has also been the case in regards to the implementation of federal recommendations and requirements. This disparity is rooted in the administration of state resources. One example is the State of Campeche. The entity decided - in coordination with Federal authorities - to reopen schools at some point, despite general closure of educational spaces ordered on a national level. In this sense, each state has sought to flatten the curve while preserving their economy and healthcare system, while also being guided by the general framework presented by the Federal authorities. To be fair, it has also amounted to adverse situations where inhabitants of certain states reported-in everyday evening conferences-their misinformation and vulnerability, apparently due to state communication policies. 
Overall, however, while facing the scenario of a deeply decentralized country, it seems plausible to admit that modulating restrictions and recommendations is a reasonable strategy. What will be interesting to see though is whether irresponsible policies_-given such case-will be held liable and how.

With regards to the social and cultural aspect, the most important feature to be taken into account is the fact that almost half of the employment in Mexico is "informal" (INEGI, 2020, p. 1). This is consistent with the general trend in the Ibero American region where the informal economic activities rate is of $62 \%$ (OCDE, 2020). The consequences of this scenario are clear: saving capacity is low and access to healthcare is complicated. Both factors, along with scarce incomes, constitute one of the most profound vulnerabilities in the region. But we should also add further challenges, such as water infrastructure, which can be very fragile in certain regions, or the distance to the nearest healthcare center.

Mexico, although it imposed at some point the closure of many services in the worst moments of the current pandemic, is facing a social dilemma inherent to pandemic governance. A strict long lockdown would have been possible had the Federation implemented a wide range of subsidiary resources. This was not the case, and we must honestly ask if such scenario would have been possible in the case of such a decentralized country. The only solution, then, seems to be a major lenience when it comes to regulating labor activities. It is plain to see that Mexico has some challenges respecting a strict "Stay at Home" mandate; requirement that is possibly difficult to implement due to a general lack of trust of workers and taxpayers towards the administration of public resources by the federal and local government.

In this context, it might be understandable that many of the policies remained as „recommendations” rather than ,requirements” and were addressed precisely in the moral and subjective dimensions. Many of them focused on general education. Despite WHO’s justified dissapointment with some Mexican leaders who were not exemplary in the use of facemasks (cfr. WHO pronouncement from November 2020), there was a major awareness campaign targeted at citizens in general. They detailed basic forms of prevention like wearing facemasks, avoiding hand-shaking and frequent hand-washing or coughing etiquette. Undoubtedly, social distancing is something which may be difficult to observe in the Mexican cultural context. Face masks in particular constitute an interesting case. While they remain at the Federal level of ,recommendation" during most of the time, they were promoted or imposed on each state level. At some point, López-Gatell expressed his rejection of certain impositions on the Federal level concerning the imposition of fines on people without facemasks. He grounded his position alluding the history of Mexico, observing that the people have already suffered enough repression. As a statesman, he did not mention the identity of the oppressor and left the hygiene policy in the hands of state authorities. However trivial this statement may sound, it does touch a very delicate issue in Mexican history.

Was the recommendation strategy excessively fragile when it came to preventing an exceedingly tragic outcome of the pandemic? While ignoring a would-be scenario, we do observe that educational campaigns have had considerable social impact, understanding the need of producing change on an individual level is certainly a valid point in the management of the pandemic. 
Unknowledgeable of whether it could go any better in a total lockdown scenario, we contend that the Mexican scenario is one of those cases where major efforts have been focused on balancing bio-economic activity and healthcare capacity. Such decisions, we believe, also respond to ethical concerns and should be examined as pursuing the best outcome. Mexico applied rules that seek, as in other countries, to flatten the curve. In order to achieve it, different recommendations were given (some of them quite common, like social distancing and hygiene measures, and constant education, some of them really unseen, as a temporal ban on alcohol sales), and some restrictions, which never amounted to a total lockdown, were established. These rules were presented in May of 2020 in the form of the Pandemic Traffic Light system in which each state is evaluated fortnightly according to the bed capacity within entity hospitals.

We therefore assume that the basic aim of the pandemic policies should be one that is spelled out in the very definition of health coined by the WHO: "a state of complete physical, mental and social well-being and not merely the absence of disease or infirmity." (WHO). It is reasonable to conclude that the Mexican measures may offer us a glimpse of an effort to balance two of the most challenging aspects of pandemic times: preventing deaths while also taking into account the situation of the population.

\section{References}

Bramble, B. (2020, 5 November). Why the orthodox Covid-19 narrative is right. The Critic, https://thecr itic.co.uk/why-the-orthodox-covid-19-narrative-is-right/

Córdova-Villalobos, J. A., Sarti, E., Arzoz-Padrés, J., et al. (2009). The influenza A(H1N1) epidemic in Mexico. Lessons learned. Health Research Policy System, 7, 21. https://doi.org/10.1186/ 1478-4505-7-21

Gobierno de México, Exceso de mortalidad en México. Retrieved December 3, 2020 from https://coron avirus.gob.mx/exceso-de-mortalidad-en-mexico/

INEGI. (2020). Estadísticas a propósito del día del trabajo. Comunicado de prensa núm.166/20. 29 April 2020. Retrieved December 29, 2020 from https://www.inegi.org.mx/contenidos/saladeprensa/aprop osito/2020/trabajoNal.pdf

Kidd, I., \& Ratcliffe, M. (2020a). Welcome to the Covid-world. The Critic, https://thecritic.co.uk/issues/ november-2020/welcome-to-covidworld/ as seen on December, 1st, 2020.

Kidd, I. J., \& Ratcliffe, M.(2020b, November 6). Why it is right to question the orhodox Covid-19 narrative. The Critic. https://thecritic.co.uk/why-it-is-right-to-question-the-orthodox-covid-19-narrative/

OCDE. (2020). COVID-19 en América Latina y el Caribe: Panorama de las respuestas de los gobiernos a la crisis. Afrontar el coronavirus (COVID-19). Acertar y salir reforzados, 11 November 2020. Retrieved from December 3, 2020 from https://www.oecd.org/coronavirus/policy-responses/covid19-en-america-latina-y-el-caribe-panorama-de-las-respuestas-de-los-gobiernos-a-la-crisis-7d9f7 $\mathrm{a} 2 \mathrm{~b} /$

WHO (2020). Frequently asked questions. Retrieved December, 29, 2020 from https://www.who.int/ about/who-we-are/frequently-asked-questions

Publisher's Note Springer Nature remains neutral with regard to jurisdictional claims in published maps and institutional affiliations. 